\title{
ANTIBACTERIAL SURVEILLANCE: AN APPROACH TO MITIGATING MULTI-DRUG RESISTANCE MENACE AMONG CLINICAL UROPATHOGENS IN EKITI STATE, NIGERIA
}

\section{Seye Julius Oladeji* and Gbenga Victor Kayejo}

Address (es): S. Julius Oladeji,

Federal University Oye-Ekiti, Faculty of Science, Department of Microbiology, Oye-Are 3, 371104 Oye-Ekiti, Ekiti State, Nigeria, phone number: +2348132754769.

Urinary tract infections (UTIs) are among the most common human infections with the distribution of etiological agents and antibiotic resistance patterns varying from region to region and from time to time. The aims of this study were to ascertain the prevalence and antibiotic resistance profiles of common Gram-negative uropathogens among patients attending a Tertiary Care Hospital in Ekiti State, Nigeria. One hundred and fifty clean-catch midstream urine specimens were obtained and cultured within 2 hours of collection for the detection of Gram-negative uropathogens. The isolated organisms were identified by standard microbiological methods. Of the total 150 urine specimens analyzed, $82(54.67 \%)$ specimens were positive for Gram-negative uropathogen with significant bacteriuria of which 34 (41.46\%) were males and $48(58.54 \%)$ were females. Klebsiella spp. $38(46.34 \%)$ and Escherichia coli $32(39.02 \%)$ were the most frequently isolated Gram-negative uropathogens, followed by Proteus mirabilis 10 (12.20\%) while the least occurring uropathogen was observed to be Pseudomonas aeruginosa 2 (2.44\%). All the isolated uropathogens were observed to be highly resistant to the commonly prescribed antibiotics. Emerging resistance to carbapenems was also observed. Nevertheless, carbapenems showed highest susceptibility compared to other tested antibiotics. Conclusively, high levels of resistance of uropathogens to antibiotics exist in our setting. This therefore calls for continuous antibiotic surveillance and improved antibiotic stewardship.

Keywords: Gram-negative uropathogens, UTIs, Antibiotic resistance, Klebsiella spp., Escherichia coli

\section{INTRODUCTION}

Urinary tract infections (UTIs) are among the most common human infections both in the community and hospital settings (Dalela $\boldsymbol{e t}$ al., 2012). UTI is the second most widespread infectious disease after respiratory tract infection in most communities (Alsohaili $\boldsymbol{e}$ al., 2015) and it is regarded as a major public health problem, owing to increased costs with an estimated 150 million cases per annum worldwide (Arjunan $\boldsymbol{e t}$ al., 2010). Urinary tract infection affects people in varying incidences, depending on age-group and gender (Agbagwa and Ifeanacho, 2015). Most times females are at greater risk, owing to the shortness of their urethra and its closeness to the anus (Okonko et al., 2009; Dielubanza et al., 2011).

The distribution of the etiological agents of urinary tract infection varies from region to region and from time to time. Theodros (2010) reported that most UTIs are caused by Gram-negative bacteria, including Escherichia coli, Klebsiella spp., Proteus mirabilis, Pseudomonas aeruginosa, Acinetobacter spp., and Serratia spp. and Gram-positive bacteria such as Enterococcus spp. and Staphylococcus spp. In addition, majority of the research work on UTIs have documented that Escherichia coli is the most common cause of UTIs (Shapiro and Donald, 2003), however, few authors have reported changing patterns in the prevalence of uropathogens (Agbagwa and Ifeanacho, 2015; Ehinmidu, 2003; Ekwealor et al., 2016).

The resistance of uropathogens to commonly used antibiotics has increased worldwide (Kahlmeter, 2003; Mazzulli, 2002). The alteration in the resistance patterns of the organisms over the last decade has resulted into serious therapeutic challenges (Magalit et al., 2004; Gur et al., 2008). Hence, the regional variations in the distribution and susceptibility of uropathogens to antibiotics necessitate the swift need for adequate knowledge about the antibiotic susceptibility patterns of the prevalent uropathogens in our area. This will help in selecting the most appropriate empirical antimicrobial therapy and further assists in the preclusion of emergence of drug-resistant bacteria strains (Yeshwondm, 2016; Timothy et al., 2014).

Hence, the objectives of our study were to determine the prevalence and resistance patterns of common Gram-negative uropathogens among patients attending a Tertiary Care Hospital in Ekiti State, Nigeria.

\section{MATERIALS AND METHODS}

\section{Study Location}

This prospective study was conducted at a Tertiary Care Hospital in Ekiti State, Nigeria over a period of eight months from March to October 2018. The respective demographic information of the patients was retrieved from the record book provided by the Hospital.

\section{Sample collection}

Urine specimens were collected in accordance to the standardised protocols as described by Cheesbrough (2006) and modified by Prakash and Saxena (2013) and Ochada et al. (2014). Clean catch midstream urine (MSU) was collected from each patient into a $20 \mathrm{ml}$ calibrated sterile screw-capped universal container which was distributed to the patients. All patients were well instructed on how to collect sample aseptically prior to sample collection to avoid contaminations from urethra. Samples collected were transported to the laboratory in ice pack and cultured within 2 hours of collection for Gram-negative uropathogen isolation.

\section{Culture and Isolation of Organism}

The urine specimens $(10 \mu \mathrm{l})$ were cultured on Cysteine Lactose Deficient agar (CLED), MacConkey, and Eosin-Methylene blue (EMB) agar simultaneously, using micropipette and incubated in aerobic conditions for 24 hours at $37^{\circ} \mathrm{C}$. Cultures without any colony at the end of $24 \mathrm{hrs}$ of incubation were further incubated for $48 \mathrm{hrs}$. Plates with colony count equal to or more than $10^{5} \mathrm{Cfu} / \mathrm{ml}$ were considered significant culture positive (Pooja et al., 2017). The organisms were further subcultured on fresh MacConkey agar plate in order to get pure culture.

\section{Identification of Isolates}

The isolates were identified and confirmed using standard biochemical tests as described by Barrow and Feltham (2003) and stored on nutrient agar slants for further study.

\section{Antibiotic Susceptibility Assay}

The antibiotic susceptibility testing was performed according to CLSI guidelines (CLSI document (M100-S21), 2015). The antibiotic discs and their

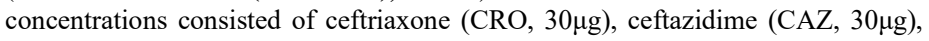

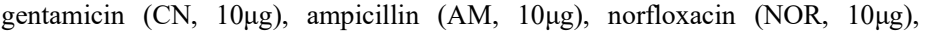
tetracycline (TE, $30 \mu \mathrm{g}$ ), ertapenem (ETP, $10 \mu \mathrm{g}$ ) and meropenem (MEM, $10 \mu \mathrm{g}$ ). Moreover, prior to antibiotic susceptibility testing, the culture was diluted in sterile normal saline $(0.9 \mathrm{v} / \mathrm{v})$ suspension and thereafter matched with the 0.5 McFarland standard (Ojo et al., 2013). 


\section{Ethical Approval}

Ethical approval with protocol number (ERC/2017/10/18/84B) was obtained before conducting the research. All research protocols were performed in accordance to the ethical standards of committees on human experimentation laid down in Helsinki declaration of 1964 revised in 2000 (World Medical Association Declaration of Helsinki, 2000).

\section{RESULTS}

A total of 150 urine specimens recommended for Urine Microscopy, Culture and Sensitivity at a Tertiary Care Hospital in Ekiti State, Nigeria were collected and analyzed. Eighty-three $(55.33 \%)$ urine specimens were collected from females while $67(44.67 \%)$ urine specimens were collected from males. Urine specimens of only $34(41.46 \%)$ males and $48(58.54 \%)$ females showed demonstrable bacteruria and they were all positive for Gram-negative uropathogens. Out of the 82 positive samples, $57(69.51 \%)$ urine specimens were from outpatients while 25 $(30.49 \%)$ urine specimens were from inpatients (Table 1).

Table 1 Percentage of Patients' Demographic Information

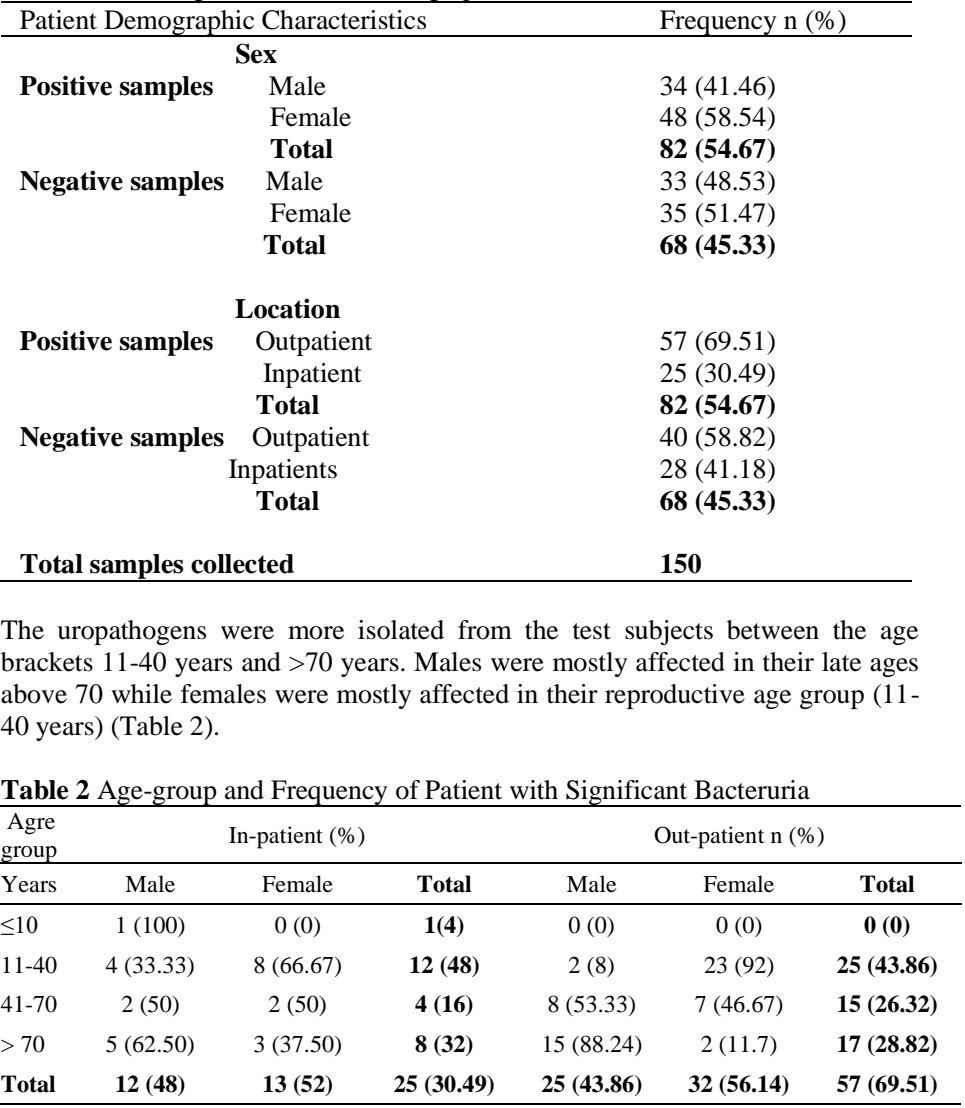

Of the total 150 urine specimens collected, 97 (64.67\%) urine specimens were from outpatients while $53(35.33 \%)$ were from inpatients. Most of the urine specimens were from Obstetrics and Gynecology department 29 (19.33\%), General Outpatient Department 23 (15.33\%), Accident and Emergency 17 (11.33\%), Urology 15 (10\%), Female Medical Ward 14 (9.33\%) and Surgical Outpatient Department 13 (8.67\%), (Fig. 1).

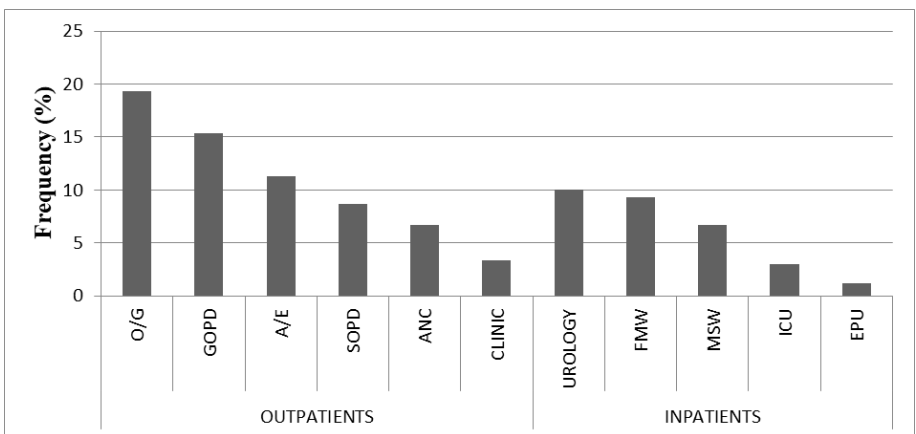

Keys: $O / G=$ Obstetrics and Gynaecology Department, GOPD = General Outpatient Department, $A / E=$ Accident and Emergency Department, $S O P D=$ Surgical Out-patient Department, ANC=Antenatal Care, FMW $=$ Female Surgical Ward, MSW= Male Surgical Ward, ICU= Intensive Care Unit, EPU= Emergency Paediatric Unit.

Figure 1 Total number of samples from each department

The most frequently isolated Gram-negative uropathogens were Klebsiella spp. 38 (46.34\%) and Escherichia coli 32 (39.02\%). The least occurring uropathogens were Proteus mirabilis $10(12.20 \%)$ and Pseudomonas aeruginosa 2 (2.44\%) (Fig. 2).

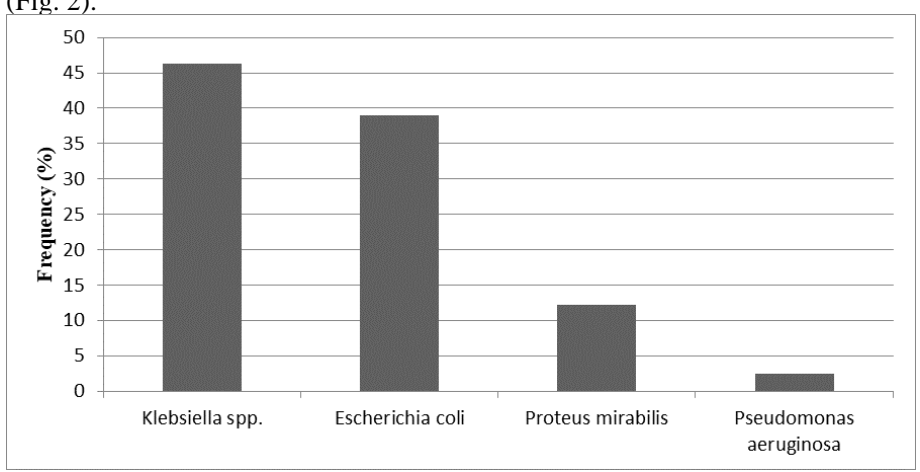

Figure 2 Frequency of the isolated uropathogens

Most of the uropathogens were isolated from Obstetrics and Gynaecology Department 18 (21.95\%), Surgical Outpatient Department 13 (15.85\%), Accident and Emergency Department 10 (12.20\%) and Female Medical Ward 10 (12.20\%) (Fig. 3).

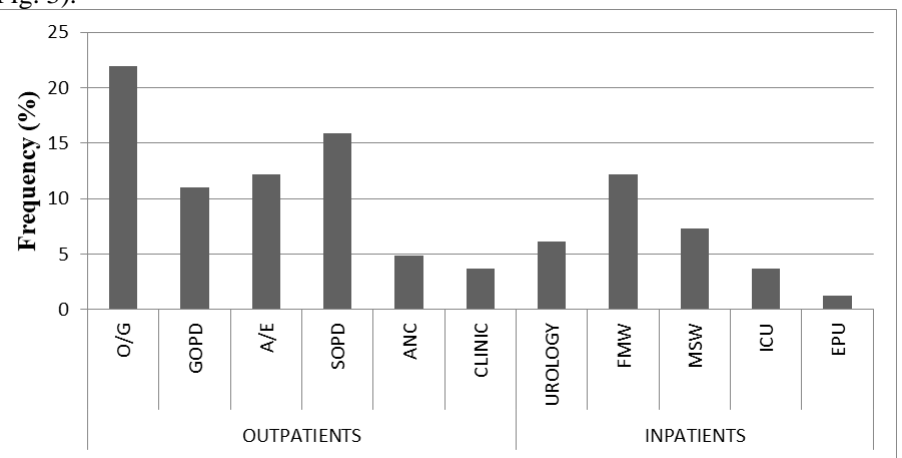

Keys: $O / G=$ Obstetrics and Gynaecology Department, GOPD= General Outpatient Department, $A / E=$ Accident and Emergency Department, SOPD= Surgical Out-patient Department, ANC=Antenatal Care, $F M W=$ Female Surgical Ward, MSW= Male Surgical Ward, ICU= Intensive Care Unit, EPU= Emergency Paediatric Unit.

Figure 3 Distribution of the isolates across department of the patients

The overall resistance rates of all the bacterial isolates to ampicillin, gentamicin, tetracycline, ceftazidime, ceftriaxone, ertapenem, meropenem and norfloxacin were observed to be $93.90 \%, 87.80 \%, 78.05 \%, 60.98 \%, 71.95 \%, 41.46 \%, 28.05 \%$ and $68.29 \%$ respectively (Table 3 ). 
Table 3 Overall antibiotic susceptibility and resistance of the isolated Gram-negative uropathogens

\begin{tabular}{|c|c|c|c|c|c|c|c|c|}
\hline & \multicolumn{7}{|c|}{ Antibiotics } & \multirow[b]{2}{*}{ MERP } \\
\hline & AMP & $\mathrm{CN}$ & TET & NOR & CFTX & CFTZ & ERTP & \\
\hline Sus n (\%) & $5(61)$ & $10(12.20)$ & 18 (21.95) & $26(31.71)$ & $23(28.05)$ & $32(39.02)$ & 48 (58.54) & 59 (71.95) \\
\hline $\operatorname{Res} \mathrm{n}(\%)$ & 77 (93.9) & $72(87.80)$ & 64 (78.05) & $56(68.29)$ & $59(71.95)$ & $50(60.98)$ & 34 (41.46) & $23(28.05)$ \\
\hline
\end{tabular}

Keys: Sus $=$ Susceptibility, Res $=$ Resistance, AMP $=$ Ampicillin, $C N=$ Gentamicin, TET $=$ Tetracycline, NOR $=$ Norfloxacin,

CFTX $=$ Ceftriaxone, $\mathrm{CEFTZ}=$ Ceftazidime, $\mathrm{ERTP}=$ Ertapenem, $\mathrm{MERP}=$ Meropenem

High resistance rate to ceftazidime, ceftriaxone, norfloxacin, gentamicin, tetracycline and ampicillin were observed in $71.05 \%, 76.32 \%, 65.79 \%, 81.58 \%$, $76.32 \%$ and $94.74 \%$ of the Klebsiella spp. isolates respectively. However, low resistance rate to meropenem and ertapenem was observed in $34.21 \%$ and $47.37 \%$ respectively. The rates of resistance among all the Gram-negative uropathogens to ampicillin, third generation cephalosporins (like ceftazidime and ceftriaxone), gentamicin, tetracycline and norfloxacin were observed to be high. The findings also revealed that $E$. coli isolates were more susceptible to meropenem and ertapenem than Klebsiella spp. isolates (Table 4).

Table 4 Antibiotic resistance of the isolated Gram-negative uropathogens

\begin{tabular}{llllllllll}
\multicolumn{2}{l}{ Table 4 Antibiotic resistance of the isolated Gram-negative uropathogens } \\
\hline \multirow{2}{*}{ Isolated Uropathogens } & No. & AMP & CN & TET & NOR & CFTX & CFTZ & ERTP & MERP \\
\hline Klebsiella spp. & 38 & $94.74 \%$ & $81.58 \%$ & $76.32 \%$ & $65.79 \%$ & $76.32 \%$ & $71.05 \%$ & $47.37 \%$ & $34.21 \%$ \\
E. coli & 32 & $100 \%$ & $87.50 \%$ & $100 \%$ & $87.50 \%$ & $56.25 \%$ & $56.25 \%$ & $12.5 \%$ & $12.5 \%$ \\
P. mirabilis & 10 & $80 \%$ & $80 \%$ & $70 \%$ & $50 \%$ & $80 \%$ & $50 \%$ & $80 \%$ & $50 \%$ \\
P. aeruginosa & 2 & $100 \%$ & $100 \%$ & $50 \%$ & $100 \%$ & $100 \%$ & $50 \%$ & $50 \%$ & $50 \%$ \\
\hline
\end{tabular}

Keys: Klebsiella $\mathrm{spp} .=$ Klebsiella species, E. coli $=$ Escherichia coli, $P$. mirabilis $=$ Proteus mirabilis, $P$. aeruginosa=
Pseudomonas aeruginosa, $\mathrm{AMP}=$ Ampicillin, $\mathrm{CN}=$ Gentamicin, $\mathrm{TET}=$ Tetracycline, NOR= Norfloxacin, CFTX= Ceftriaxone, CEFTZ= Ceftazidime, $\mathrm{ERTP}=$ Ertapenem, $\mathrm{MERP}=$ Meropenem

\section{DISCUSSION}

The present results showed that Klebsiella spp. and E. coli were the most frequently isolated uropathogens. This finding is in agreement with that of Agbagwa and Ifeanacho (2015) in Rivers State, Nigeria, where Klebsiella spp. and E. coli were the most isolated Gram-negative uropathogens. However, this contradicts the reports in other studies, where Pseudomonas aeruginosa (Ehinmidu, 2003) and Staphylococcus aureus (Ekwealor et al., 2016) were observed as the most common cause of UTIs. The similarities and differences in the type and distribution of uropathogens in the current study and other studies conducted thus far in different countries may be due to source of the specimens, patients involved, various environmental conditions and host factors (Ani and Mgbechi, 2008)

The high prevalence of UTIs $(54.67 \%)$ recorded in the present study is comparable to UTI prevalence rates reported by various authors in India 53.5\% (Prakash and Saxena, 2013) and Cameroon 59.8\% (Nzaline et al., 2016). However, the prevalence rate in the present study is higher than those recorded in previous studies which account for 4.2\% (Bigwan and Elijah, 2013), 17.19\% (Akram et al., 2007) and 29.3\% (Barrow and Feltham, 2003). These disparities in the prevalence rates may be due to the differences in methodology used, the environment, social habits of the community, the standard of personal hygiene and education (Yeshwondm, 2016).

The high incidence of UTI among female patients compared to male patients in the present study could be attributed to the physiological and anatomical differences in males and females (Agbagwa and Ifeanacho, 2015). However, the reduction of UTI in males may be attributed to the longer distance between the anus and urethra meatus and the dry environment in the urethra of males which reduces microbial growth (Prakasam et al., 2012; Kibret and Abera, 2014). This finding agrees with the report of Agbagwa and Ifeanacho (2015) in Rivers State, Nigeria, Swetha et al. (2014) and Okonko et al., (2009), where UTI occurrences were higher in females than males.

The highest rate of infection recorded in female subjects between the age group 11-40 years among both inpatient and outpatient could be due to the relatively higher sexual activity that is observed in the age group and multiple sex partners while the high incidence of UTI observed in males above 70 years may be due to the presence of a number of risk factors, including prostatic enlargement found in males, diabetes mellitus, interventional instrumentations like catheterization and weak bladder sphincter that arise due to age advancement (Moore $\boldsymbol{e t}$ al., 2002). These findings corroborate with the findings from the studies carried out by Chedi et al. (2009) in Kano, Nigeria where female patients between 21-30 years and males $>60$ years had highest frequency rate. However, these findings are in contrast with the findings from others studies, where the prevalence of UTI increases with increasing age for both sexes (Ani and Mgbechi, 2008; Nicolle, 2011).

Urine specimens were more obtained from outpatients 94 (77\%) than inpatients $28(23 \%)$, meaning that most cases were coming in directly from the community. This is in agreement with the studies from Nigeria (Iregbu and NwajiobiPrincewill, 2013), Botswana (Renuart, 2013) and the United States (Doyle et al., 2001). The high prevalence of UTI recorded among patients in Obstetrics and Gynaecology department in the present study agrees with the findings of Devi and Rajkumar (2012), who reported that the risk of UTI is most prevalent among patients with gynaecological problems.

In the present study, majority of the isolates showed resistance to commonly employed drugs in the treatment of UTIs. However, meropenem was broadly the most sensitive drug, followed by ertapenem and these are not drugs often deployed as first line of treatment of uncomplicated UTI. This is in agreement with the study carried out by Iregbu and Nwajiobi-Princewill (2013) who reported similar antibiotic resistance patterns. However, this contradicts the findings in various studies from different part of the world where resistant rates reported were different (Ehinmidu, 2003; Raza et al., 2011). The indiscriminate use and misuse of antibiotics and the consumption of substandard antibiotics as earlier reported by Okeke and Lamikanra (1995) might have over the years contributed to the high rate of antibiotic resistance observed in the present study.

\section{CONCLUSION}

The results indicated that Klebsiella spp. and Escherichia coli isolates are the most common cause of UTI in our environment. All the isolates showed high resistance to all the tested antibiotics, except meropenem and ertapenem. This therefore suggests the need for continuous antibiotic surveillance and practice of antibiotic stewardship will assist in the preclusion of further occurrences of resistance in clinical isolates and hence, expediting treatment. Also, efforts should be made towards the meticulous utilization of cephalosporins and carbapenems through the sensitization of the public by the Governmental Agency so as to maintain the efficacity of these antimicrobial agents.

Acknowledgements: The authors extend their sincere appreciation to the Department of Microbiology at Federal University Oye-Ekiti for using their laboratory to carry out bench work.

Author's Contributions: The research idea was conceptualized and designed by Seye Julius Oladeji. Data acquisition, draft preparation, writing, analysis and interpretation were carried out by Seye Julius Oladeji and Gbenga Victor Kayejo. Final review and editing were done by Seye Julius Oladeji. 


\section{REFERENCES}

Agbagwa, O., \& Ifeanacho, E. (2015). The Prevalence of UTI Pathogens in Urine Specimen Obtained from a Hospital in Rivers State, Nigeria. Journal of Microbiology Research, $\quad$ 5(5), 143-148. http://dx.doi.org/10.5923/j.microbiology.20150505.01

Akram, M., Shahid, M., \& Khan, A. U. (2007). Etiology and antibiotic resistance patterns of community-acquired urinary tract infections in JNMC Hospital Aligarh, India. Annals of clinical microbiology and antimicrobials, 6(1), 4.

Alsohaili, S. A., Alharahsheh, M. H., Almshagbeh, M. A., Alkhawaldeh, R. A., \& Alkhawaldeh, W. M. (2015). Bacterial pathogen in urinary tract infection and antibiotic resistance pattern in Zaraqa-Jordan. European Scientific Journal,12, 71-76.

Ani, O., \& Mgbechi, E. (2008). Prevalence of Urinary Tract Infections (UTI) In Sexually Active Women of Abakaliki, Ebonyi State, Nigeria. Animal Research International, 5(2), 876-87.

Arjunan, M., Al-Salamah A. A., \& Amuthan, M. (2010). Prevalence and antibiotics susceptibility of uropathogens in patients from a rural environment, Tamilnadu. Am J Inf dis., 6, 29-33. http://dx.doi.org/10.3844/ajidsp.2010.29.33

Barrow, G., \& Feltham, R. (2003). Cowan and Steel manual for identification of medical bacteria, 2003, 94-150.

Bigwan, E., \& Elijah, D. (2013). Prevalence of Escherichia coli among uropathogens in asymptomatic bacteriuria in a Nigerian Tertiary School in Jos, Nigeria. International Journal of Biomedical and Advance Research, 4(3), 198202.

Chedi, B. A., Wannang, N. N., Halliru, M. A., \& Bichi, L. A. (2009). A seven months retrospective study on urinary tract Infection among patients at Aminu kano teaching hospital, Kano-Nigeria. Bayero J Pure Appl Sci., 2, 95-8.

Cheesbrough, M. (2006). District Laboratory Practice in Tropical Countries. 2nd Edition, Cambridge University Press, 2006, 64-70.

Clinical and Laboratory Standards Institute guidelines. (2015). Performance Standards for Antimicrobial Susceptibility Testing, Twentieth Informational Supplement. Wayne, PA, USA: $C L S I$.

Dalela, G., Gupta, S., Jain, D. K., \& Mehta, P. (2012). Antibiotic resistance pattern in uropathogens at a tertiary care hospital at Jhalawar with special reference to Esbl, Ampc $\beta$-Lactamase and MRSA production. J Clin Diagn Res., 6, 645-651.

Devi, S., \& Rajkumar, J. (2012). Investigation of Bacterial Pathogens Responsible for Urinary Tract Infection in Human Subjects. J. Med. Sci., 12(7), 234-238. http://dx.doi.org/jms.2012.234.238

Dielubanza, E., Aisha, K. T., Teresa, R., Zembower, S., Robert, B., Nadler, D., Marc, H. S., John, P. C., Diana, B., Adam, B. M., \& Anthony, J. S. (2011). Targeted Antimicrobial Prophylaxix using Rectal Swab Cultures in Men in association with Reduced Incidence of Post operative Infectious Complications and Cost Care. The journal of Urology, 187, 1275-1279.

Doyle, B., Mawji, Z., Horgan, M., Stillman, P., Rinehart, A., Bailey, J., \& Mullin, E. J. (2001). Decreasing nosocomial urinary tract infections in a large academic Community Hospital. Lippincotts Case Manag., 6(3), 127-36.

Ehinmidu, J. (2003). Antibiotics susceptibility patterns of urine bacterial isolates in Zaria, Nigeria. Trop J Pharm Res., 2(2), 223-8.

Ekwealor, P. A., Ugwu, M. C., Ezeobi, I., Amalukwe, G., Ugwu, B. C., Okezie, U., ... \& Esimone, C. (2016). Antimicrobial Evaluation of Bacterial Isolates from Urine Specimen of Patients with Complaints of Urinary Tract Infections in Awka, Nigeria. International Journal of Microbiology, 2016. http://dx.doi.org/10.1155/2016/9740273

Gür, D., Gülay, Z., Akan, O. A., Aktas, Z., Kayacan, C. B., Cakici, O., ... \& Uysal, S. (2008). Resistance to newer beta-lactams and related ESBL types in gram-negative nosocomial isolates in Turkish hospitals: Results of the multicentre HITIT study. Mikrobiyol Bul., 42, 537-44.

Iregbu, K., \& Nwajiobi-Princewill, P. (2013). Urinary Tract Infections in a Tertiary Hospital in Abuja, Nigeria. Afr. J. Cln. Exper. Microbiol., 14(3):169-173. http://dx.doi.org/10.4314/ajcem.v14i3.9

Kahlmeter, G. (2003). An international survey of the antimicrobial susceptibility of pathogens from uncomplicated urinary tract infections: The ECO.SENS Project. J Antimicrob Chemother., 51, 69-76.

Kibret, M., \& Abera, B. (2014). Prevalence and antibiogram of bacterial isolates from urinary tract infections at Dessie Health Research Laboratory. Ethiopia. Asian Pac J Trop Biomed., 4(2), 164-168.
Magalit, S. L., Gler, M. T., \& Tupasi, T. E. (2004). Increasing antimicrobial resistance patterns of community and nosocomial uropathogens in Makati Medical Center. Phil J Microbiol Infect Dis., 33, 143-8.

Mazzulli, T. (2002). Resistance trends in urinary tract pathogens and impact on management. J Urol., 168, 1720-2.

Moore, K. N., Day, R. A., \& Albers, M. (2002). Pathogenesis of urinary tract infections: a review. J Clin Nurs., 11(5), 568-74.

Nicolle, L. (2011). The chronic in dwelling catheter and urinary infection in longterm-care facility residents, Infect Control Hosp Epidemiol., 22(5), 316-21.

Nzaline, R. N., Gonsu, K. H., \& Koulla-Shiro, S. (2016). Bacterial Etiology and Antibiotic Resistance Profile of Community-Acquired Urinary Tract Infections in a Cameroonian City. International Journal of Microbiology, 2016: Article ID 3240268 .

Ochada, N. S., Nasiru, I. A., Thairu, Y., Okanlowan, M. B., \& Abdulakeem, Y. O. (2014). Antimicrobial Susceptibility pattern of urinary pathogens isolated from two Tertiary Hospitals in south western Nigeria. African Journal of Clinical and Experimental Microbiology, 16(1), 12-22. http://dx.doi.org/10.4314/ajcem.v16i1.3 Ojo, S. K., Ejims-Enukwe, O. \& Esumeh, F. I. (2013). In-vitro antibacterial timekill assay of Phyllanthus amarus and Diodia scandens crude extracts on Staphylococci isolated from wounds and burns patients. International Journal of Pharmaceutical Science, 2(8), 9-11.

Okonko, I. O., Donbraye-Emmanuel, O. B., Ijandipe, L. A., Ogun, A. A., Adedeji, A. O., \& Udeze, A. O. (2009). Antibiotics Sensitivity and Resistance Patterns of Uropathogens to Nitrofurantoin and Nalidixic Acid in Pregnant Women with Urinary Tract Infections in Ibadan, Nigeria. Middle-East Journal of Scientific Research, 4(2), 105-109.

Pooja, S., Dhiraj, S., Elina, M., Vijay, K. S., \& Rabin, P. (2017). ESBL Production Among E.coli and Klebsiella spp. Causing Urinary Tract Infection: A Hospital Based Study. The Open Microbiology Journal, 11, 23-30. http://dx.doi.org/10.2174/1874285801711010023

Prakasam, A. K. C., Kumar, K. G. D., \& Vijayan, M. (2012). A Cross-Sectional Study on Distribution of Urinary Tract Infection and Their Antibiotic Utilization Pattern in Kerala. Int J Pharm Tech Res., 4(3), 1309-1316.

Prakash, D., \& Saxena, R. (2013). Distribution and Antimicrobial Susceptibility Pattern of Bacterial Pathogens Causing Urinary Tract Infection in Urban Community of Meerut City, India. International Scholarly Research Notices: Microbiology-Hindawi, Article ID 749629. http://dx.doi.org/10.1155/2013/749629

Raza, S., Pandey, S., \& Bhatt, C. (2011). Microbiological Analysis of the Urine Isolates in Kathmandu Medical College Teaching Hospital, Kathmandu, Nepal. Kathmandu Univ. Med J., 9(36), 295-7.

Renuart, A. (2013). Microbiology of Urinary Tract Infections in Gaborone, Botswana. PLoS One, 8(3). http://dx.doi.org/10.1371/journal.pone.0057776

Shapiro, D., \& Donald, R. (2003). Exposure of Laboratory Workers to Francisella tularensis despite a Bioterrorism Procedure. J. Clin. Microbiol., 40, 2278-2281

Swetha, V. V., Rao, U. S., Prakash, P. H., \& Subbarayudu, S. (2014). Aerobic Bacteriological Profile of Urinary Tract Infections in a Tertiary Care Hospital. Int J Curr Microbiol App Sci., 3(3), 120-125.

Theodros, G. (2010). Bacterial pathogens implicated in causing urinary tract infection (UTI) and their antimicrobial susceptibility pattern in Ethiopia. Revista CENIC. Ciencias Biológicas, 41: 1-6.

Timothy, O. O., Olusesan, F. J., Adesola, B. O., Temitayo, A. A., David, F. O., \& Ige, O. O. (2014). Antibiotic resistance pattern of bacterial isolates from cases of urinary tract infections among hospitalized and out-patients at a tertiary health facility in South Western Nigeria. Ann Trop Med Public Health, 7, 130-5. http://www.atmph.org/text.asp?2014/7/2/130/146403

World Medical Association Declaration of Helsinki (2000). Ethical Principles for Medical Research Involving Human Subjects, e 52nd WMA General Assembly, Edinburgh, Scotland, 2000.

Yeshwondm, M. (2016). Antibiotic Resistance Patterns of Common Gramnegative Uropathogens in St. Paul's Hospital Millennium Medical College, Addis Ababa, Ethiopia. Ethiop J Health Sci., 26(2), 93-99. 